\title{
Empathy and understanding down under
}

\author{
The Patient: One Man's Journey Through \\ the Australian Health-care System \\ Dr. Mohamed Khadra \\ William Heinemann Australia; 2009. \\ 240 pp (A)\$43.95
}

$\mathrm{T}$ his book offers an unexpectedly poignant and absorbing exploration of the experiences of a middle-aged man dealing with a serious illness within the Australian health care system. Unexpected, because the patient's story also serves as a vehicle for the sometimes blistering critique of the Australian health care system by the author, a urologist and professor of surgery at the University of Sydney.

The central character Jonathan Brewster - who is suffering from bladder cancer - is based on a composite of the author's cancer patients.

Brewster's incompetent surgeon is another composite, drawn from public records and hearsay. But the book is "as true and accurate a reflection of what takes place in Australian hospitals every day, from both the patients' and doctors' points of view, as I could render from my own experiences," Khadra writes.

The Patient is both a cautionary tale for all who are, or might become, hospital patients, and a concerned doctor's crie de coeur. This insider's critique is unlikely to make Khadra friends among health ministers and high-level government bureaucrats.

The book tackles as central issues the inefficiency and inhumanity of Australia's parallel private and public systems of health care in which patients pay out-of-pocket, or significant amounts above their insurance coverage, to gain quicker access to care in private hospitals than is possible in the depleted, overburdened public hospital system.

Brewster's experiences illustrate the conflicts of interest that arise when physicians (in this case, surgeons) are

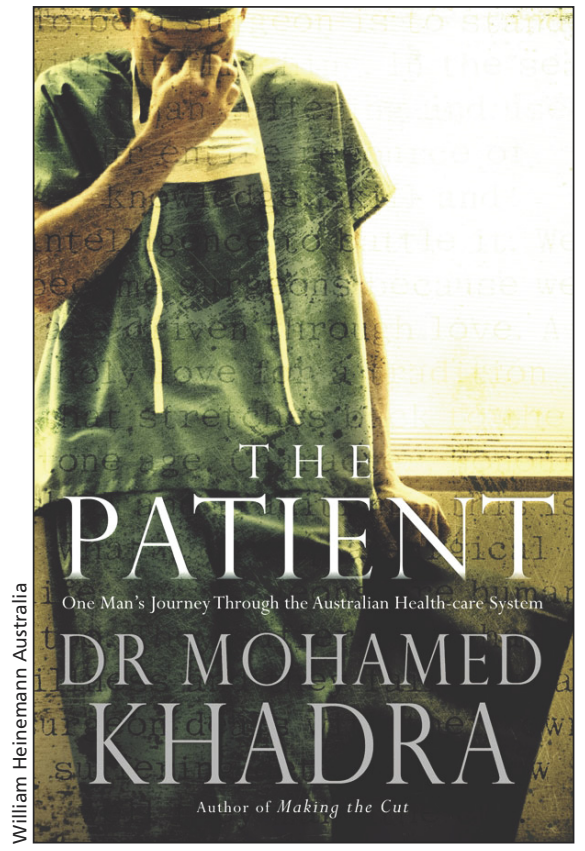

able to work in both the public and private system and steer patients to their more profitable private practices.

In his earlier, bestseller, Making the Cut, A Surgeon's Stories of Life on the Edge (2007), Khadra recounts his decision to give up private practice to become a salaried doctor. "I could then, with conscience intact, advise patients as to what they would need and not what I would want for my future financial survival."

Canada does not have the same public-private divide in health care, but many of the fictional Brewster's experiences are familiar to anyone who has spent time in Canadian hospitals: long waits, last-minute cancellations, outsourcing of vital services like cleaning (with resulting lower standards), the necessity of making decisions about one's own care in less than ideal circumstances, and the uneven quality of inhospital medical and nursing care.

But the strength of The Patient, and what makes it so poignant, is Brewster's encounter with his mortality. Brewster is not immediately a sympathetic character. He is a middle-aged, ambitious, competitive, status-conscious, financially stretched businessman with little time for his young children. Yet as he grapples with his unexpected illness, the reader is drawn to him and his chance encounters - some brutalizing, others uplifting - with a range of fellow patients and other characters.

And woven in with Brewster's experiences are the behind-the-scenes events as observed by Khadra, who places himself, in the first person, as a character in the narrative. Through his eyes, we gain some insight into the surgeons' challenges, survival mechanisms, weaknesses and strengths. Surgeons 'dip in and out of our patients' lives much like a flying insect touches on a pond," writes Khadra, observing that "the technical repair of the patient was the means of displaying care."

In Making the Cut, Khadra wrote that society "needs technically competent, brave, even arrogant surgeons whose strength is derived from perfecting the craft." Perhaps a callous disregard for death is a "necessary part of our survival," he muses. "Or perhaps surgery was blunting my humanity."

But later, telling the story of his own hospitalization, Khadra wrote that he yearned for "comfort in this place of discomfort. I did not want to be a lump of meat in a bed." Khadra's experience of being a patient was a turning point that prompted a shift in his working life: He recently left active surgery to establish an institute designed to aid medical students in developing countries. This latest book is clearly another product of that shift from the doctor's to the patient's perspective.

Brewster's journey is not just a narrative device to illustrate a doctor's critique. There is real empathy and understanding here.

\section{Ann Silversides MA \\ News Journalist, CMAJ \\ Ottawa, Ont.}

